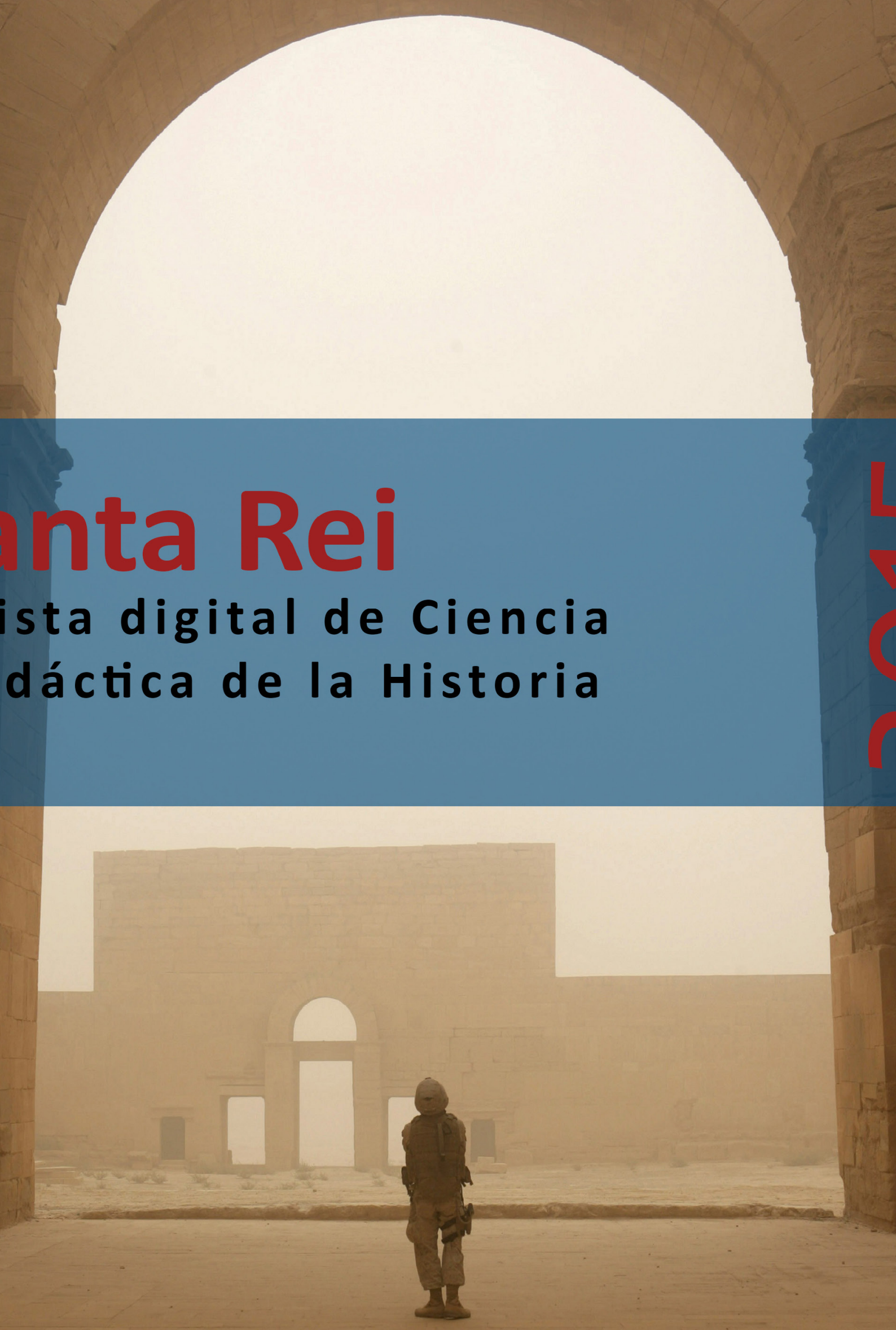

Revista digital de Ciencia y Didáctica de la Historia 


\section{Panta Rei \\ Revista Digital de Ciencia \\ y Didáctica de la Historia}

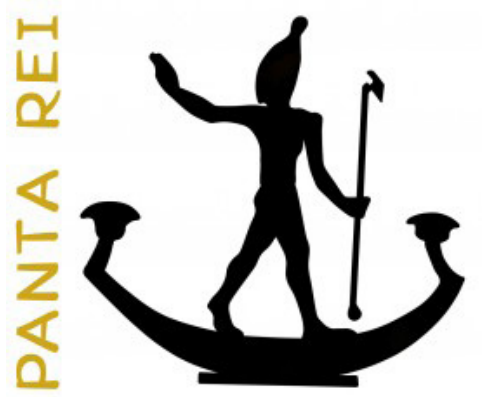

\section{5}

Revista anual

Fecha de inicio: 1995

Revista Panta Rei. pantarei@um.es

Edita:

Centro de Estudios del Próximo Oriente y la Antigüedad Tardía - CEPOAT

Edificio Universitario Saavedra Fajardo.

Universidad de Murcia

C/ Actor Isidoro Máiquez, 9

30007 - MURCIA - ESPAÑA

Teléfono: (+34) 868883890

cepoat@um.es

Web: www.um.es/cepoat/pantarei

Edición 2015

ISSNe: 2386-8864

ISSN: 1136-2464

Depósito legal: MU-966-1995
cepoAt

UNIVERSIDAD DE MURCIA centro de estudios del próximo oriente y la antigüedad tardía

En Portada: Ruinas de Hatra (Irak) (Fotografía de: Lance Cpl. Albert F. Hunt, U. S. Marine Corps).

Responsables de los textos: Sus autores.

Responsable de la presente edición: Consejo Editorial Panta Rei. 


\section{CONSEJO DE REDACCIÓN}

\section{Coordinador editorial}

Egea Vivancos, Alejandro

[Didáctica de las Ciencias Sociales, UMU]

\section{Editores}

Botí Hernández, Juan Jesús

[CEPOAT, UMU]

Meseguer Gil, Antonio José

[CEPOAT, UMU]

Sáez Giménez, David Omar

[CEPOAT, UMU]

Sánchez Mondéjar, Celso Miguel

[CEPOAT, UMU]

\section{Secretaria}

Arias Ferrer, Laura

[Didáctica de las Ciencias Sociales, UMU]

\section{Responsable informático}

Martínez García, José Javier

[CEPOAT, UMU]

\section{Traducción y corrección lingüística}

Martínez Martínez, Cristina

[Sociedad Española de Lenguas Modernas]

\section{CONSEJO ASESOR}

Albero Muñoz, M. ${ }^{a}$ del Mar [H. ${ }^{a}$ del Arte, UMU]

Chapman, Arthur

[History Education, UCL, Reino Unido]

Cobacho López, Ángel

[Derecho, UMU]

Egea Bruno, Pedro M. ${ }^{\text {a }}$

[Historia Contemporánea, UMU]

García Atienzar, Gabriel

[Prehistoria, UA]

González Monfort, Neus

[Didáctica de las Ciencias Sociales, UAB]

Haber Uriarte, María

[Prehistoria, UMU]

Irigoyen López, Antonio

[Historia Moderna, UMU]

Mahony, Simon

[Digital Humanities, UCL, Reino Unido]

Marsilla de Pascual, Francisco Reyes

[Técnicas historiográficas, UMU]

Miralles Maldonado, José Carlos

[Filología Clásica, UMU]

Molina Gómez, José Antonio

[Historia Antigua, UMU]

Noguera Celdrán, José Miguel

[Arqueología, UMU]

Pérez Molina, Miguel Emilio

[Filología Clásica, UMU]

Prados Martínez, Fernando

[Arqueología, UA]

Sánchez Ibáñez, Raquel

[Didáctica de las Ciencias Sociales, UMU]

Sancho Gómez, Miguel Pablo

[Educación, UCAM]

Vilar García, María José

[Historia Contemporánea, UMU] 

Artículos

El patrimonio arqueológico iraquí y su destrucción a lo largo del tiempo.

Fernando Espejel Arroyo.

Tacita Muta y el silencio femenino como arma del patriarcado romano.

Sara Casamayor Mancisidor.

Espartaco en la arqueología.

Juan Luis Posadas.

La batalla de Andagoste.

Luis Amela Valverde.

Las trabas para una formación arqueológica inclusiva.

Ana Samaniego Espinosa.

Repensando las narrativas nacionales: Un análisis del origen, transmisión e influencia en el aprendizaje histórico.

César López Rodríguez

El profesor como predicador, provocador y ermitaño. Un pre-texto para pensar las tareas de la didáctica de la historia.

Enrique Ibáñez Rojo

Entrevista

Evaluando el desarrollo de la competencia histórica en la enseñanza de la Historia en España. Entrevista a Jesús Domínguez Castillo.

María José Morales Rodríguez.

Reseñas

II Congreso de Jóvenes Investigadores del Mundo Antiguo de la Universidad de Murcia.

Pedro David Conesa Navarro y Juana M. ${ }^{a}$ Martínez Molina.

II Jornadas Internacionales de Didáctica de la Historia.

Eusebio Manuel Vidal Abellán.

Dölger, F. J. (2015). La luz de Cristo. Madrid: Ediciones Encuentro. 98 págs.

Alejandro Ruiz Sánchez.

Cooper, H. (ed.) (2013). Teaching History Creatively. Londres: Routledge. 185 págs.

Marta Gil de Sola Bellas.

El arte paleolítico en El Carnicero de Chabrol.

Alberto Lombo Montañés.

Normas de publicación/Publishing rules 



\title{
Tacita Muta y el silencio femenino como arma del patriarcado romano
}

\author{
Tacita Muta and the feminine silence as a weapon of the roman \\ patriarchy
}

\author{
Sara Casamayor Mancisidor ${ }^{1}$ \\ Universidad de Salamanca
}

Recibido: $27 / 01 / 15$

Aceptado: 10/08/15

Para citar este artículo: Casamayor Mancisidor, S. (2015). Tacita Muta y el silencio femenino como arma del patriarcado romano. Panta Rei. Revista Digital de Ciencia y Didáctica de la Historia, 27-41.

ISSNe: $2386-8864$

DOI: http://dx.doi.org/10.6018/pantarei/2015/2

\section{Resumen}

Tacita Muta fue una náyade a la que Júpiter arrancó la lengua por hablar más de la cuenta. Convertida en divinidad, simbolizaba para los romanos la prerrogativa del silencio femenino. El objetivo del presente artículo es el de, tomando como punto de partida el mito de Tacita, ilustrar cómo el patriarcado romano impuso a las mujeres la obligatoriedad del silencio. Además, se presentan diversos ejemplos de divinidades, personajes mitológicos y mujeres reales que también ejemplificaron esta característica femenina, junto con otros que transgredieron la norma establecida. Todo ello con el objetivo de profundizar en las relaciones de género de época romana.

\section{Palabras clave}

Mujer, Roma antigua, Relaciones de género, Mitología

\section{Abstract}

Tacita Muta was a naiad punished by Jupiter who ripped her tongue out for talking excessively. She became a divinity that symbolized the prerogative of the feminine silence. The aim of the present article is to illustrate how the roman patriarchy imposed the duty of silence on women, taking the myth of Tacita as the starting point. We present several examples of deities, mythological characters and real women who also exemplified this female duty, along with others that transgressed the norm. All of this with the aim of getting deeper on gender relations in Roman times.

\section{Keywords \\ Woman, Ancient Rome, Gender relations, Mythology}

1 Para contactar con la autora: saric@usal.es 


\section{Introducción}

En el libro segundo de los Fastos, Ovidio nos habla de la náyade Lara, también conocida como Lala o Tacita Muta, quien fue cruelmente castigada por hablar más de la cuenta. Su historia traspasó las fronteras de la mitología y sirvió para dar ejemplo a las mujeres romanas: aquélla que hablase cuando no debía podía sufrir un castigo terrible. No obstante, la interpretación del mito ovidiano va más allá si se estudia en profundidad; además, la historia de Tacita Muta no fue la única forma en la que la sociedad patriarcal romana impuso a las mujeres una personalidad forzosamente silenciosa, castigando a quienes rompieran con la regla establecida.

En este sentido, la lectura de éste y otros mitos nos permite analizar la labor de estas historias como "transmisoras del orden simbólico patriarcal" y como forma de delimitar "las funciones de cada sexo en la sociedad clásica" (Guerra, 2006, p. 176). No en vano, los mitos contribuían "al reparto desequilibrado de los roles sexuales, al dominio en definitiva de los varones sobre las mujeres" (Pérez, 2011, p. II), y se constituyen como una de las estrategias de imposición de una cultura normativa que legitima estas relaciones de dominio (Beteta, 2009). Por lo tanto, el estudio de las relaciones de género en Roma no concierne sólo a las mujeres antiguas, sino también a los hombres, ya que la interacción entre ambos, o la imposición de ciertos valores por parte de los segundos a las primeras, es la que construye las estructuras de género².

Así, los mitos se erigen como una construcción social que sirve al patriarcado romano para imponer modelos o representaciones ideales de comportamiento a la sociedad en general y, en lo que respecta a este artículo, a las mujeres (López-Saco, 2009). El mito forma parte de un proceso de construcción de identidades que articula, vertebra, y codifica la conducta en sociedad a partir de narraciones, imágenes y todo tipo de representaciones culturales que perfilan las conductas, experiencias y percepciones de aquellos que lo transmiten y lo reciben (Beteta, 2009). Un discurso que ha sido creado por los hombres y que, en cuanto hegemónico, define "el papel social de las mujeres, siempre en desventaja en privilegios, derechos y deberes" (Cid, 2015, p. 41). Por ello, cuando en estas líneas nos referimos al silencio femenino, no sólo aludimos a las romanas, en cuanto sufridoras de este precepto, sino también a los romanos, en calidad de creadores del mismo. Preceptos, normas y valores que acabaron siendo interiorizados por las propias mujeres y de ese modo se transmitieron de generación en generación mediante un fenómeno que se ha dado en llamar de socialización (Pilcher y Wherehan, 2011), convirtiendo a las romanas en garantes de la supervivencia de la mentalidad patriarcal.

El objetivo del presente artículo es el de realizar un análisis del mito de Tacita Muta desde una perspectiva de género, ilustrando cómo el patriarcado romano se sirvió de esta divinidad para inculcar a las romanas la prerrogativa del silencio femenino. Para ello, se ha estructurado en tres partes fundamentales. En la primera se analiza el mito de Tacita Muta tomando como hilo conductor el texto ovidiano y poniendo especial énfasis en la significación del silencio femenino. En la segunda parte del texto se presentan una serie de personajes femeninos, míticos, legendarios o religiosos, que también sirvieron a los romanos para trasmitir a sus mujeres la obligatoriedad del silencio. Finalmente, se analizan casos de mujeres que rompieron con la regla establecida y las reacciones que la sociedad patriarcal tuvo al respecto de estas transgresiones.

\section{Tacita Muta. El mito y su trascendencia}

La referencia más conocida a Tacita Muta la encontramos en la obra Fastos de Ovidio. El autor comienza describiéndonos el ritual religioso consagrado a Tacita, en el que participan tanto una anciana como mujeres jóvenes, para después relatar el mito que le dio origen:

2 Un reciente repaso por la historiografía dedicada a los estudios de género y de la mujer en la Antigüedad lo encontramos en Cid (2015). 


\begin{abstract}
Ahora querrás saber por mí quién es la diosa Muta. Aprende lo que me es conocido por los viejos de antaño. Júpiter, vencido por el amor desmesurado de Yuturna, aguantó mucho, lo suficiente para un dios de su categoría. Ella, ora se ocultaba entre los avellanares de la selva, ora saltaba a las aguas, con ella emparentadas. Júpiter reunió a las ninfas, cualesquiera que habitaban en el Lacio, y les espetó las siguientes palabras en medio del corro: "Vuestra hermana tiene celos de sí misma y evita acostarse con el dios supremo, cosa que le sería provechosa. Ocuparos de los dos, pues si mi placer ha de ser grande, grande será el beneficio de vuestra hermana. Cuando eche a huir, poneos delante de ella al borde de la orilla para que no zambulla el cuerpo en el agua del río». Esto dijo. Todas las ninfas del Tíber asintieron y también las que agasajan tu tálamo, divina llia. Casualmente había una náyade, de nombre Lara, aunque su nombre antiguo tenía la primera sílaba duplicada por error. Almón le había dicho muchas veces: "Hija, contén la lengua», pero ella no la contenía. Así que dio con el lago de su hermana Yuturna, le dijo: "Aléjate de las orillas», y le refirió las palabras de Júpiter. También visitó a Juno y le dijo, compadeciéndose de las casadas: "Tu marido está enamorado de la náyade Yuturna». Júpiter se encolerizó y arrancó a la náyade la lengua de que se había servido imprudentemente, y llama a Mercurio: "Llévatela donde los Manes; ése es el lugar apropiado para los silenciosos. Será ninfa, pero ninfa de la laguna soterrada». Se cumplen las órdenes de Júpiter. El bosque acogió a los que llegaban; se cuenta que ella entonces resultó del agrado del dios que la conducía. Éste se aprestaba a la violencia, ella suplicaba con el rostro sustituyendo las palabras, esforzándose en vano por hablar con su boca muda. Quedó embarazada y parió dos gemelos: los Lares, que guardan y vigilan siempre las encrucijadas de nuestra ciudad ${ }^{3}$.
\end{abstract}

(Ou., Fast. II, 585-615)

El trasfondo del mito nos es del todo familiar: Júpiter se ha enamorado de una criatura, ya sea humana o no, como en este caso, y como padre supremo de los dioses está decidido a conseguir sus atenciones a pesar de que ella rechace su compañía. Sólo este hecho ya dice mucho de la forma en la que los romanos afrontaban las relaciones de género a través de sus mitos; no importa lo que al respecto opine Yuturna, ella no es dueña de su sexualidad, sino sufridora del "amor desmesurado de Júpiter". Como señala Guerra, "la superestructura ideológica de la época permitía que se manifestase el deseo del hombre mientras que el de la mujer debía ser silenciado" (2006, p. 178). De la misma forma, Tacita es violada por Mercurio en una escena atroz, mientras se resiste con una súplica que resulta muda a consecuencia de la mutilación sufrida como castigo a su charlatanería. Como ocurre con otras historias míticas como la del rapto de las sabinas o la de la concepción de Rómulo y Remo, la libre disposición del cuerpo femenino por parte del varón es un hecho que parece irremediable. Una situación que podía empeorar si la mujer era especialmente

3 Protinus a nobis quae sit dea Muta requires: disce per antiquos quae mihi nota senes. luppiter, inmodico luturnae victus amore, multa tulit tanto non patienda deo: illa modo in silvis inter coryleta latebat, nunc in cognatas desiliebat aquas. Convocat hic nymphas, Latium quaecumque tenebant, et iacit in medio talia verba choro: 'invidet ipsa sibi vitatque quod expedit illi vestra soror, summo iungere membra deo. Consulite mbobus: nam quae mea magna voluptas, utilitas vestrae magna sororis erit. Vos illi in prima fugienti obsistite ripa, ne sua fluminea corpora mergat aqua.' Dixerat; adnuerant nymphae Tiberinides omnes quaeque colunt thalamos, Ilia diva, tuos. Forte fuit Nais, Lara nomine; prima sed illi dicta bis antiquum syllaba nomen erat, ex vitio positum. Saepe illi dixerat Almo 'nata, tene linguam': nec tamen illa tenet. Quae simul ac tetigit luturnae stagna sororis, 'effuge' ait 'ripas', dicta refertque lovis. Illa etiam lunonem adiit, miserataque nuptas 'Naida luturnam vir tuus' inquit 'amat.' Iuppiter intumuit, quaque est non usa modeste eripit huic linguam, Mercuriumque ocat: 'duc hanc ad manes: locus ille silentibus aptus. Nympha, sed infernae nympha paludis erit.' lussa lovis fiunt. Accepit lucus euntes: dicitur illa duci tum placuisse deo. Vim parat hic, voltu pro verbis illa precatur, et frustra muto nititur ore loqui, fitque gravis geminosque parit, qui compita servant et vigilant nostra semper in urbe Lares. 
bella; es por ello que en las Metamorfosis, otra obra de Ovidio, tanto Coronis de Larisa como Cenis se lamentan de su apariencia (Ou., Met. II, 569-576 y XII, 189-197). Así se expresa la primera de ellas:

Mi hermosura me dañó: pues, cuando por los litorales con lentos pasos, como suelo, paseaba por encima de la arena, me vio y se encendió del piélago el dios, y como suplicando con blandas palabras tiempos inanes consumió, la fuerza dispone y me persigue; huyo y denso dejo el litoral, y en la mullida arena me fatigo en vano ${ }^{4}$

(Ou., Met. II, 569-576)

Fruto de la violación sufrida, Lara queda embarazada y pare a los gemelos Lares, encargados de vigilar los confines de la ciudad. Con todo, la cuestión central de este mito no es la de la violencia sexual, ni la de la obediencia debida a los dioses, sino la del silencio femenino. El silencio, empleado como castigo, imposición, o virtud sumisa, sólo puede darse, tal y como indica Segarra (2007), en una sociedad que se halle repleta de sonidos. Y la romana lo era. Los sonidos, convertidos en palabras, eran el modo de vida de los rétores, el arma de los oradores y los políticos, el honor final rendido a los fallecidos en forma de elogio funerario, la plasmación de la piedad para con la familia y los seres queridos en las inscripciones funerarias, y el entretenimiento en las conversaciones de los banquetes. No obstante, y si nos detenemos en este punto, observaremos que todos esos usos de la palabra se le atribuyen al hombre adulto y ciudadano romano, distinguiéndolo de esta forma del animal por su capacidad de pensar, razonar y expresar sus ideas mediante el habla, proporcionándole "properties like glory-seeking and autonomy that are associated with masculinity" y creando una identidad "as free, male, and Roman" (Connolly, 2007, pp. 4-5) ${ }^{5}$. Y es ese mismo ciudadano quien impone a otros el silencio, quien les retira o restringe el uso de la palabra cuando percibe la existencia de una amenaza. En este sentido, el peligro de la expresión femenina radicaba en que, si las mujeres usaban la palabra con demasiada frecuencia, podían convertirla en un mero mecanismo de trasmitir banalidades y chismes. No sólo eso, sino que, desde el punto de vista romano, el discurso femenino estaba vacío de contenido, y era un discurso descentrado y basado en la emoción (Kruschwitz, 2012). Así, la historia de Tacita es:

la historia de una mujer ligera, incauta, irreflexiva, que había hecho mal uso de una cualidad de la que, usada del modo correcto, los romanos se sentían muy orgullosos: la palabra. (...) Además esto no había ocurrido casualmente. (...) Lara usó la palabra a destiempo, de modo inoportuno, "porque era una mujer», es decir, inevitablemente, respondiendo a un defecto típicamente femenino.

(Cantarella, 1997, pp. 20-21)

La festividad en honor a Tacita Muta se celebraba el 21 de febrero. La diosa era considerada una divinidad de los muertos, no sólo por su lugar de destino sino porque el silencio es también característico de la muerte. Castigada por desobedecer a Júpiter, quien por otro lado encarna la figura del todopoderoso paterfamilias, es sin embargo premiada al convertirse en una divinidad a partir del momento en el que es privada del uso de la palabra y por lo tanto puede personificar el ideal femenino. Según nos cuenta Plutarco (Plu., Num. VIII), el culto a Tacita Muta fue instaurado por Numa, quien devolvió a Roma numerosas divinidades antiguas. En lo que respecta al cumplimiento de los rituales religiosos en honor a Tacita Muta, los pasos a realizar son según Ovidio los siguientes:

4 Forma mihi nocuit. nam cum per litora lentis passibus, ut soleo, summa spatiarer harena, vidit et incaluit pelagi deus, utque precando tempora cum blandis absumpsit inania verbis, vim parat et sequitur. fugio densumque relinquo litus et in molli nequiquam lassor harena.

5 Añade aquí Connolly (2007, p. 4) que "women stand outside the circle, in the company of the poor, immigrants, and other classes legally or culturally determined to lack the authority necessary to act in the political arena". 
He aquí que una vieja cargada de años se sienta entre las muchachas y cumple con el rito de Tacita aunque ella misma no se está callada (taceo), y coloca en la parte de atrás del umbral tres granos de incienso con tres dedos, en el punto donde un minúsculo ratón se ha abierto un camino oculto. A continuación ata un trompo encantado a un trozo de plomo oscuro, y remueve en la boca siete habas negras, y quema al fuego la cabeza de un pececillo que ha untado de alquitrán y cosido atravesándolo con una aguja de cobre. También vierte vino; el vino que queda se lo bebe o ella misma o las acompañantes, aunque ella más. "Hemos amordazado las lenguas de los enemigos y las bocas hostiles», dice la vieja conforme se va, saliendo borracha ${ }^{6}$.

(Ou., Fast. II, 570-580)

Además de la mención a la relación entre la divinidad y el silencio, existen otros aspectos a destacar del ritual ovidiano. Por un lado, en él se menciona la participación tanto de una mujer anciana como de mujeres jóvenes. Por lo que parece, se trata de un culto destinado únicamente a las mujeres, lógico si consideramos que Tacita era la personificación del silencio femenino. Nos encontramos por lo tanto ante un culto clasificatorio, por cuanto exclusivamente femenino. La edad no es una característica restrictiva, ya que toman parte en él tanto una anciana como muchachas. Sin embargo, no podemos descartar que, como muchos otros cultos en la Antigua Roma, se exigieran otros requisitos para poder cumplir con el ritual, tales como determinada posición social o estado civil $^{7}$. Por otro lado, y en cuanto a la celebración del culto en sí, Marco (2010) lo describe como un ritual simpático; es decir, uno cuyo fin era el de provocar en el destinatario un efecto concreto. Se basa para ello no sólo en la descripción de Ovidio, sino también en dos inscripciones halladas en Cambodunum (Raetia) y Siscia (Pannonia Superior) ${ }^{8}$. El propósito del ritual que nos describe Ovidio sería el de enmudecer la lengua de la persona objeto de la magia, "acallar las maledicencias" en palabras de Cantarella (1997, p. 20), acción que se ve reforzada al coser al pez, animal mudo por excelencia. A este respecto, Marco señala que el deseo de impedir que se hable en contra de uno es "uno de los objetivos más reiterados en las inscripciones mágicas" (2010, p. 109)9.

Si existía una divinidad que personificaba el silencio femenino, también nos encontramos con otra que simboliza la capacidad de hablar del varón romano. Se trata de Aius Locutius, quien, desde su mismo nombre, nos indica cuál es su principal característica. La importancia de esta divinidad radica en que fue quien avisó a los romanos de que se acercaba una invasión gala en el año 391 a.C. El episodio, según lo narra Plutarco, es el siguiente:

La primera señal que hubo de que amenazaba algún gran mal fue la muerte del censor Julio, porque los Romanos respetan mucho esta autoridad, y la miran como sagrada. Fue la segunda, que antes del destierro de Camilo un hombre, no de los ilustres ni de los senadores, pero sí tenido por de probidad y rectitud, llamado Marco Cedicio, dio cuenta a los magistrados de una cosa muy digna de atención. Dijo que en la noche precedente iba por la calle que decian Nueva, y sintiendo que le llamaban con una gran voz, se volvió a ver lo que era, y aunque no vio a nadie, oyó una voz más que

6 Ecce anus in mediis residens annosa puellis sacra facit Tacitae (vix tamen ipsa tacet), et digitis tria tura tribus sub limine ponit, qua brevis occultum mus sibi fecit iter: tum cantata ligat cum fusco licia plumbo, et septem nigras versat in ore fabas, quodque pice adstrinxit, quod acu traiecit aena, obsutum maenae torret in igne caput; vina quoque instillat: vini quodcumque relictum est, aut ipsa aut comites, plus tamen ipsa, bibit. 'Hostiles linguas inimicaque vinximus ora' dicit discedens ebriaque exit anus.

7 Referencias a cultos femeninos clasificatorios y su simbolismo las encontramos en Cid (2007a).

8 Las inscripciones, según las cita el autor, se encuentran en $A E$ 1958, 150 y AlJ 255-257.

9 Para profundizar más en las atribuciones mágicas del culto a Tacita Muta, ver Bettini (2006). 
humana, que le dijo: "Oye, Marco Cedicio, ve de mañana y anuncia a los magistrados que se dispongan a recibir dentro de poco a los Galos ${ }^{10}$.

Según Tito Livio (Liv., L, 5) la voz que avisó a Marco Cedicio fue la de Aius Locutius. Sin embargo, el senado hizo caso omiso de Cedicio, con funestas consecuencias (Saggioro, 2007). Puede que por ello, y a pesar de que se le construyese un altar en su honor, Aius no volviera a pronunciarse jamás (Cic., Diu. II, 69). No obstante, lo que deja claro este episodio en comparación con la historia de Tacita y en relación al simbolismo mitológico romano es lo siguiente: los hombres hablan, la mujer perfecta no debe excederse en el uso de la palabra. Tal y como escribe Lagarde, en el orden patriarcal, "el sujeto dominante se constituye en voz, razón, imagen y representación" (Lagarde, 2014, p. 17), por lo que es el único con capacidad de hablar y de expresarse. Por otro lado, y siendo la posesión del cuerpo femenino una de las armas empleadas por el patriarcado para afirmar su poder sobre la mujer (López-Medina, 2009), la apropiación de su voz, el negarle el uso de la palabra a excepción de cuando se considera adecuado, se convierte en una herramienta más de dominación. "Per la donna romana il silenzio era non tanto una virtù quanto un dovere: un silenzio che, tranne i rari casi rappresentati da donne che né la conditio naturae né la verecundia stolae riuscirono a zittire in foro et in iudiciis" (Buonopane, 2009, p. 231).

Un deber que, mediante ejemplos como el de Tacita, los cuales conocería toda la sociedad romana y formarían parte de su identidad común (Dixon, 2001), pretendían enseñar a las mujeres cómo debían comportarse (Langlands, 2000). El destino de Tacita sería narrado a las jóvenes romanas para mostrarles el castigo que podían sufrir si no se comportaban de acuerdo a lo que se esperaba de ellas (López-Medina, 2009), y las representaciones visuales del mito servirían de recordatorio para todo aquel que ya conociera la historia. Así las romanas, aunque excluidas de la construcción de los mitos, sirvieron como instrumento de naturalización de la ideología dominante, transmitiendo las madres a las hijas los valores patriarcales, al tiempo que, formando parte de los relatos míticos, se convertían en idealizaciones sobre las que reposaban los estereotipos femeninos (Beteta, 2009). Con ello, este episodio mitológico sirvió como elemento legitimador de la imposición de la mudez femenina (López-Saco, 2009). El silencio se convirtió, junto a otras características como la pasividad o el recato, en uno de los principales atributos de una buena matrona, en la externalización de su recto comportamiento y su pudicitia (Sissa, 2008). Con ello, una historia sobre los dioses, que como todo episodio mitológico supone un reflejo de la sociedad que lo crea, se convierte, a través de su difusión e interiorización, en un relato con función ejemplarizante, un exemplum, el cual servía para recordar cuál era su lugar a esas mujeres romanas que, como señala Richlin, (1992) parecen situarse de continuo en la frontera entre el modelo ideal y la transgresión.

\section{Otros mitos, divinidades y personajes ilustradores del silencio femenino}

La historia de Tacita Muta no fue la única forma mediante la cual los romanos impusieron a las mujeres el silencio como prerrogativa. Las fuentes nos proporcionan otros muchos ejemplos de figuras femeninas caracterizadas por la ausencia de palabra, ya formen parte de los mitos o de la realidad histórica.

El primero de esos ejemplos lo encontramos de nuevo en la obra de Ovidio. Se trata del mito de Pigmalión (Ou., Met. X, 245-295), rey de Chipre que, no pudiendo encontrar la mujer deseada,

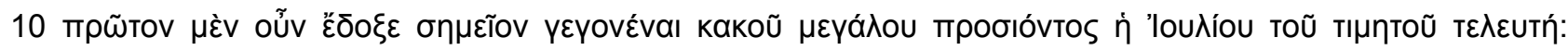

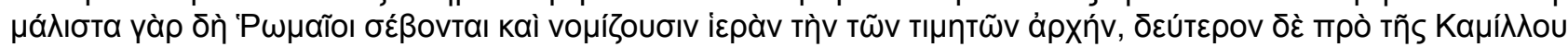

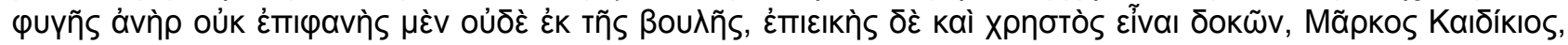

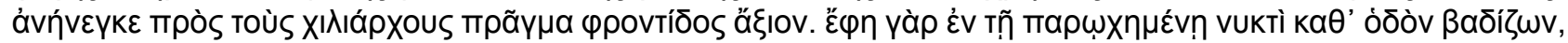

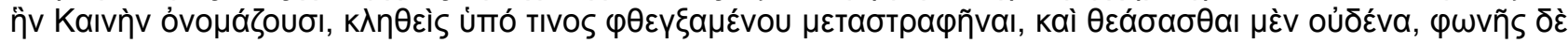

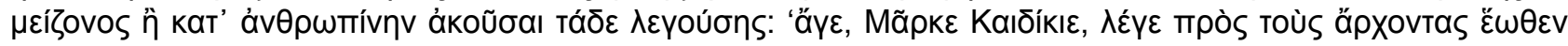

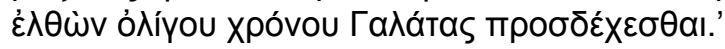


esculpió él mismo una a partir de una pieza de marfil. Entusiasmado del resultado, pidió a Venus que diese vida a la estatua, y terminó casándose con la mujer a la que él mismo había moldeado.

Cuando volvió, los remedos busca él de su niña y echándose en su diván le besó los labios: que estaba templada le pareció; le allega la boca de nuevo, con sus manos también los pechos le toca. Tocado se ablanda el marfil y depuesto su rigor en él se asientan sus dedos y cede, como la del Himeto al sol, se reblandece la cera y manejada con el pulgar se torna en muchas figuras y por su propio uso se hace usable. Mientras está suspendido y en duda se alegra y engañarse teme, de nuevo su amante y de nuevo con la mano, sus votos vuelve a tocar; un cuerpo era: laten tentadas con el pulgar las venas. Entonces en verdad el Pafio, plenísimas, concibió el héroe palabras con las que a Venus diera las gracias, y sobre esa boca finalmente no falsa su boca puso y, por él dados, esos besos la virgen sintió y enrojeció y su tímida luz hacia las luces levantando, a la vez, con el cielo, vio a su amante ${ }^{11}$.

(Ou., Met. X, 280-295)

Lo que esta historia pretende transmitir es lo siguiente: la única mujer perfecta es aquella creada según los deseos del hombre y a conveniencia de éste. No sólo eso, sino que la actitud de ésta debe ser totalmente complaciente y pasiva; cuando Pigmalión da vida a la estatua, la forma que tiene de descubrir que ella ya no es un trozo inerte de marfil es tocarle los pechos y ver cómo éstos ceden ante la presión. La única reacción de ella es la de sonrojarse. Una reacción que, como vemos, es muda, tal y como debe ser la mujer y esposa perfecta. En palabras de Rodríguez, el mito de Pigmalión y otros de igual corte otorgan:

superioridad al hombre, haciéndole creador y modelador de la mujer mientras que a ella le corresponde el papel de ser la receptora de la sabiduría que él le va dictando, convirtiéndola en un personaje pasivo, sumiso y sin voz propia, pues recibe, interioriza y tiene que asumir como propio el conocimiento que le es trasmitido.

(Rodríguez, 2010, p. 33)

Al igual que la estatua de Pigmalión, silenciosa era también la divinidad romana Angerona, cuya festividad, la Angeronalia, se celebraba el 21 de diciembre. Según Plinio (Plin., HN III, 65), era una diosa del silencio que se representa amordazada. Para Macrobio (Macr., Sat. III, 9), no se trataba de una mordaza, sino que la diosa se tapaba la boca con el dedo, otro símbolo del silencio ${ }^{12}$. Añade Macrobio que este gesto hizo creer a algunos que Angerona podía ser la custodia del verdadero nombre de Roma, el cual no debía conocerse, y por ello la divinidad pedía silencio.

No obstante, los ejemplos del silencio femenino trascienden el espacio mítico y religioso. Así, en época tardorrepublicana nos encontramos con una matrona cuya actitud la convirtió en imagen de la pudicitia femenina, entendida como virtud y moderación. Se trata de Sempronia, hija de Cornelia y hermana de los Graco. Según Valerio Máximo (Val. Max., III, 8), en el año 102 a.C. el censor Metelo Numídico había incluido en el censo como ciudadano a un hombre llamado Lucio Equicio. De él se sospechaba que se había hecho pasar por hijo de Tiberio Graco, y Sempronia fue

11 Ut rediit, simulacra suae petit ille puellae incumbensque toro dedit oscula: visa tepere est; admovet os iterum, manibus quoque pectora temptat: temptatum mollescit ebur positoque rigore subsidit digitis ceditque, ut Hymettia sole cera remollescit tractataque pollice multas flectitur in facies ipsoque fit utilis usu. Dum stupet et dubie gaudet fallique veretur, rursus amans rursusque manu sua vota retractat. Corpus erat! Saliunt temptatae pollice venae. Tum vero Paphius plenissima concipit heros verba, quibus Veneri grates agat, oraque tandem ore suo non falsa premit, dataque oscula virgo sensit et erubuit timidumque ad lumina lumen attollens pariter cum caelo vidit amantem.

12 Para profundizar en el debate de cómo se encontraba cerrada la boca de Angerona y si su silencio era impuesto o voluntario, ver Dubordieu (2003). 
llamada a testificar para confirmar o desmentir que Equicio era su sobrino. ¿Cómo debía hacerlo? Dando un beso al sospechoso en caso de que éste fuera quien decía ser, ya que éste era un gesto que una mujer sólo podía tener para con un familiar. Sempronia se negó a besar a Equicio, expresando así que éste había cometido un fraude. Valerio Máximo alaba la actitud de Sempronia, cuyos ilustres parentescos masculinos cita, al tiempo que ataca a Equicio:

Así pues, te citaré a ti, Sempronia, hermana de Tiberio y Cayo Graco, y esposa de Escipión Emiliano (...) Porque, presentada por un tribuno de la plebe ante la asamblea del pueblo, supiste mantener la nobleza de tus antepasados, en medio de la más terrible confusión. (...) La más alta autoridad de la república te hostigaba con torva faz y profiriendo amenazas que nada bueno presagiaban; en tus oídos zumbaba el griterío de una enloquecida multitud y todo el pueblo, congregado en el foro, se empeñaba con el más encendido afán de que dieras, como a hijo de tu hermano Tiberio, un beso a aquel Equicio para quien se reclamaban los derechos de pertenecer al tronco familiar de los Sempronios. Tú, sin embargo, rechazaste a aquel monstruo, surgido de no sé qué mundo de tinieblas, que pretendía con la más execrable de las audacias usurpar un parentesco que no le correspondía ${ }^{13 .}$

(Val. Max., III, 8.6)

Lo más relevante de este episodio en lo que concierne al presente artículo es el hecho de que la hermana de los Graco no se expresó de viva voz, sino mediante un gesto, convirtiéndose así en ejemplo de la modestia y el silencio femeninos. Con ello, entroncaba con su madre, Cornelia, quien personificó durante la época tardorrepublicana el modelo ideal de feminidad (Casamayor, 2015; Dixon, 2007). Por otra parte, Bauman apuesta por que la actitud de Sempronia se debe, no a su pudicitia, sino más bien a su posicionamiento político (Bauman, 1992).

\section{Mujeres que hablan, mujeres que transgreden la norma}

Como hemos visto a lo largo de las páginas anteriores, a las mujeres romanas les estaba prohibido el uso de la palabra en público o en exceso. El discurso femenino "is associated with lack of decorum, a lack of the proper verecundia or sense of modesty" (Langlands, 2000, p. 176). En el mito de Tacita, la transgresión conllevaba un castigo terrible: la privación de la palabra, la violación y la reclusión en el inframundo. Si bien en la antigua Roma las mujeres no debieron sufrir igual destino que la náyade, aquellas que hicieron impropio uso de la palabra fueron diana de la opinión pública y padecieron los ataques de distintos personajes, los cuales han llegado hasta nosotros. Lamentablemente, no podemos saber qué opinaban las romanas al respecto, ya que todos los autores que nos permiten estudiar estas transgresiones son hombres.

Las romanas recibían una educación similar a la de sus familiares masculinos en los primeros años de su vida y una vez casadas era deber del esposo seguir instruyéndolas, por lo cual toda matrona debía tener unos conocimientos mínimos de filosofía y retórica, entre otros aspectos. Los logros intelectuales se consideraban aspectos que engrandecían a la matrona, y se veían como una consecuencia de la especial cultura de sus progenitores y esposos, como veremos más adelante cuando nos refiramos a Hortensia. Así, estas romanas debían de ser capaces de llevar una

13 Itaque te, Sempronia, Ti. et C. Gracchorum soror, uxor Scipionis Aemiliani, non ut absurde te grauissimis uirorum operibus inserentem, maligna relatione conprehendam, sed quia ab tribuno plebei producta ad populum in maxima confusione nihil a tuorum amplitudine degenerasti, honorata memoria prosequar. Coacta es eo loci consistere, ubi principum ciuitatis perturbari frons solebat, instabat tibi toruo uultu minas profundens amplissima potestas, clamore imperitae multitudinis obstrepens totum forum acer rimo studio nitebatur ut Equitio, cui Semproniae gentis falsum ius quaerebatur, tamquam filio Tiberii fratris tui osculum dares. tu tamen illum, nescio quibus tenebris protractum portentum, execrabili audacia ad usurpandam alienam propinquitatem tendentem reppulisti. 
conversación culta en cualquier reunión social. No obstante, y la obligatoriedad del silencio de por medio, la matrona no debía intentar alardear de sus conocimientos con pedantería si no deseaba generar un rechazo como el expresado por Juvenal en el siguiente pasaje, donde además de elogiar la capacidad de contención de la mujer ideal, el autor muestra el miedo a que los conocimientos de la esposa puedan sobrepasar los del marido:

Pero ella se hace más pesada, porque apenas se recuesta en la mesa, empieza a cantar las glorias de Virgilio, perdona a Elisa a punto de matarse, presenta a un mismo tiempo a los poetas, y compara, de una parte pone a Virgilio y en el otro platillo de la balanza coloca a Homero. Se retiran los gramáticos, se declaran vencidos los rétores. Todos callan, no hablará ni el abogado, ni el pregonero, ni siquiera otra mujer. Habla con tal torrente de palabras, que dirías que resuenan toda clase de vajillas y de campanas. (...) La que es prudente pone el fin debido incluso a las cosas honestas, pues la que se empeña en parecer demasiado docta y elocuente, debe arregazar sus túnicas hasta la mitad del muslo, sacrificar a un puerco a Silvano y lavarse por un cuadrante. (...) Siento odio contra aquélla que consulta y aprende el arte de Palemón, observando siempre las leyes y las normas del habla y que repite versos antiguos que yo no conozco, y reprende a la amiga no letrera palabras de las que se preocupan los hombres. „Permítase al marido decir algún solecismo que otro! ${ }^{14}$.

(luu., VI)

Como se infiere de las palabras de Juvenal, el pecado de la mujer a la que ataca no es el uso de la palabra, sino hablar demasiado, sin mostrar la moderación propia de la matrona, la sobriedad que debía caracterizar a la mujer casada de la élite. "Si ellas se callan es porque la mujer que se calla vale más que la que habla"15, escribe Plauto (Rud., 114). Por otro lado, el satírico parece especialmente enfadado porque la habladora resta protagonismo a los hombres que se encuentran a la mesa, no sólo a su marido sino también a aquellos a quienes deja mudos con su palabrería e incluso al propio Juvenal, ya que recita versos que él desconoce. En este punto, vemos cómo al silencio femenino como medida de salvaguardar los asuntos privados de los hombres se le añade otra razón: la idea, incluso el miedo, de que las mujeres pudieran superar a los varones en el uso de la palabra. Un temor masculino a perder su posición preeminente que podemos observar en otros autores; así, por ejemplo, ante el descontento femenino por la lex Oppia en el año 195 a.C., Tito Livio pone en boca de Catón lo siguiente:

Si cada uno de nosotros, Quirites, hubiese aprendido a mantener sus derechos y su dignidad de marido frente a la propia esposa, tendríamos menos problemas con las mujeres en su conjunto; ahora, nuestra libertad, vencida en casa por la insubordinación de la mujer, es machacada y pisoteada incluso aquí en el foro, y como no fuimos capaces de controlarlas individualmente, nos aterrorizan todas a la vez. (...) Desde el momento

14 Illa tamen grauior, quae cum discumbere coepit laudat Vergilium, periturae ignoscit Elissae, committit uates et comparat, inde Maronem atque alia parte in trutina suspendit Homerum. Cedunt grammatici, uincuntur rhetores, omnis turba tacet, nec causidicus nec praeco loquetur, altera nec mulier. uerborum tanta cadit uis, tot pariter pelues ac tintinnabula dicas pulsari. lam nemo tubas, nemo aera fatiget: una laboranti poterit succurrere Lunae. Inponit finem sapiens et rebus honestis; nam quae docta nimis cupit et facunda uideri crure tenus medio tunicas succingere debet, caedere Siluano porcum, quadrante lauari. Non habeat matrona, tibi quae iuncta recumbit, dicendi genus, aut curuum sermone rotato torqueat enthymema, nec historias sciat omnes, sed quaedam ex libris et non intellegat. Odi hanc ego quae repetit uoluitque Palaemonis artem seruata semper lege et ratione loquendi ignotosque mihi tenet antiquaria uersus nec curanda uiris. Opicae castiget amicae uerba: soloecismum liceat fecisse marito.

15 Eo tacent, quia tacitast melior mulier semper quam loquens. 
mismo en que comiencen a ser iguales, serán superiores ${ }^{16}$.

A las mujeres les estaba prohibido actuar en la vida pública, donde el arma principal era el uso de la palabra. En consecuencia, los deberes ciudadanos eran calificados como "viriles"17. Por ello, la actitud de las dos mujeres que se presentan a continuación es sin duda transgresora, ya que ambas actuaron como abogadas, oficio reservado a los romanos que dominaban la palabra de forma excepcional. Si bien las romanas podían defenderse a sí mismas, no podían ejercer como abogadas de terceros ${ }^{18}$. Las razones las expone Ulpiano:

En segundo término, se propone un edicto (del pretor) en relación con aquellos que no pueden abogar por otros (ante él). En este edicto el pretor estableció exclusiones por razón del sexo y de algunos defectos, y designó también a las personas señaladas por la nota de infamia. En cuanto al sexo, prohíbe que las mujeres aboguen por otro, y la razón de la prohibición es evitar que las mujeres se mezclen en causas ajenas, en contra del pudor propio de su sexo, y desempeñen oficios viriles ${ }^{19}$.

No obstante, y aunque a las romanas no les estuviera prohibido defenderse a sí mismas, eso no significa que no se tratase de una transgresión a la obligación del silencio femenino y que por ello aquellas que lo hiciesen fueran atacadas por los autores de la época. Ulpiano (Dig., 3.1.1.5.) menciona a continuación el nombre de Carfania, cuya actitud provocó la publicación del edicto que describe. Sobre esta mujer, Ilamándola en este caso Caya Afrania, nos habla también Valerio Máximo:

Caya Afrania (...) siempre dispuesta a meterse en pleitos, defendió en todo momento sus causas ante el pretor, no porque careciese de abogados, sino porque le sobraba desenvoltura. Así pues, haciendo temblar las salas de los tribunales con sus gritos, cosa desacostumbrada en el foro, llegó a ser un ejemplar único de la intriga femenina, hasta el punto de que a las mujeres de malas costumbres se les suele apodar con el calumnioso apelativo de "Caya Afrania". Ésta prolongó su existencia hasta el año en que Julio César fue nombrado cónsul por segunda vez, con Publio Servilio. Decimos esto, porque de un monstruo semejante es preciso hacer saber a los venideros más el año de su desaparición que el de su nacimiento ${ }^{20}$.

(Val. Max., VIII, 3.2)

16 Si in sua quisque nostrum matre familiae, Quirites, ius et maiestatem uiri retinere instituisset, minus cum uniuersis feminis negotii haberemus: nunc domi uicta libertas nostra impotentia muliebri hic quoque in foro obteritur et calcatur, et quia singulas sustinere non potuimus uniuersas horremus.

17 Un análisis en profundidad en clave de género sobre el tema de los oficios viriles lo encontramos en Höbenreich (2005).

18 Para la intervención femenina en los juicios en época Julio-Claudia, ver Deline (2009).

19 Secundo loco edictum proponitur in eos, qui pro aliis ne postulent: in quo edicto excepit praetor sexum et casum, item notavit personas in turpitudine notabiles. Sexum: dum feminas prohibet pro aliis postulare et ratio quidem prohibendi, ne contra pudicitiam sexui congruentem alienis causis se immisceant, ne virilibus officiis fungantur mulieres.

20 C. Afrania uero Licinii Bucconis senatoris uxor prompta ad lites contrahendas pro se semper apud praetorem uerba fecit, non quod aduocatis deficiebatur, sed quod inpudentia abundabat. Itaque inusitatis foro latratibus adsidue tribunalia exercendo muliebris calumniae notissimum exemplum euasit, adeo ut pro crimine inprobis feminarum moribus C. Afraniae nomen obiciatur. Prorogauit autem spiritum suum ad C. Caesarem iterum $P$. Seruilium consules: tale enim monstrum magis quo tempore extinctum quam quo sit ortum memoriae tradendum est. 
Afrania era la esposa del senador Lucio Bucco. La fecha de su muerte, inferida de la información proporcionada por Valerio Máximo, es la del año 49 a.C. La actitud de Afrania es tan reprochable que el historiador prefiere datar su muerte antes que su nacimiento. A pesar de que tenía derecho a defenderse a sí misma, es calificada de monstruo por ello. Las razones son varias. Por un lado, pudiendo contratar a un abogado, y por lo tanto, pudiendo preservar su pudor, Afrania decide presentarse ella misma ante los tribunales, y no sólo una vez, sino varias. Por otro lado, para Valerio su único propósito es el de causar revuelo, demostrar su falta de vergüenza y, en su condición de mujer, llenar el foro de gritos. Gritos, que no palabras, asemejándola más al animal irracional que en la mentalidad patriarcal era la mujer que a un ser humano con capacidad de raciocinio. Otro rasgo atribuido a las mujeres en la cultura romana y que posee Afrania es el de la intriga. Las mujeres, que no pueden perseguir sus propios intereses dentro de la vida ciudadana -ya que carecen de la capacidad de ocupar cargos públicos y de hacer uso de la palabra; capacidad que, por otra parte, son los hombres quienes se la han negado-, lo hacen de forma oculta, subrepticia, mediante el chismorreo, las intrigas y el uso de venenos. Además, su mal comportamiento sirve para crear, al igual que ocurría con Tacita Muta, un ejemplo a evitar, convirtiéndose su nombre en un insulto que cualquier matrona virtuosa desearía eludir.

No obstante, y a pesar de que Valerio Máximo señale que el objetivo de Afrania al presentar tantas demandas era el de la simple diversión, en ningún momento menciona que perdiera alguno de los casos, dato que habría reforzado su mala imagen.

En el breve apartado dedicado por este autor a las mujeres que actuaron como abogadas, a quienes califica como inmodestas e impúdicas (Val. Max., VIII, 3), se menciona también a Mesia.

Habiendo sido acusada Mesia Santinas, defendió su causa ante los jueces, presididos por el pretor Lucio Ticio, y en medio de un gran concurso del pueblo. Desarrolló regularmente todas las partes de la defensa con talento e incluso energía, por lo que fue absuelta en el primer juicio casi por unanimidad. A esta mujer, porque bajo su aspecto femenino escondía un alma varonil, le pusieron el sobrenombre de Andrógina ${ }^{21}$.

(Val. Max., VIII, 3.1)

Comparando este texto con el referido a Afrania, Mesia sale mejor parada. No sólo es absuelta en un proceso que Höbenreich (2005) identifica como una quaestio, sino que incluso se intuye cierta admiración por parte de Valerio Máximo. No la ataca, como hiciera con Afrania, por representarse a ella misma, y no iguala sus palabras a gritos, sino que destaca su talento oratorio. No obstante, se trata de un talento que no es propio de una mujer; de ahí que la llame andrógina y le adjudique un alma de varón. Un gran halago, si tenemos en cuenta la estructura social en la que ambos personajes se mueven; al compararla con un hombre, eleva a Mesia del estatus inferior de mujer.

El comparar a féminas talentosas con hombres no es algo raro en el ámbito romano. El mismo Valerio Máximo (VIII, 3) nos presenta otro ejemplo cuando describe el discurso, recogido también por Apiano (BC, 32-33) que Hortensia realizó en el año 42 a.C. delante de los triunviros Octaviano, Marco Antonio y Lépido con el objeto de que las familiares de los proscritos no se vieran despojadas de sus bienes ${ }^{22}$. Valerio destaca la habilidad oratoria de Hortensia y no señala nada reprochable en su comportamiento, a pesar de que el atreverse a pronunciar un discurso en pleno foro constituye sin duda una transgresión de la norma del silencio femenino. Como motivos de su juicio, que nada tiene que ver con el que tiene sobre Afrania, pueden señalarse dos. Por un lado, y si leemos el

21 Amesia Sentinas rea causam suam L. Titio praetore iudicium cogente maximo populi concursu egit modosque omnes ac numeros defensionis non solum diligenter, sed etiam fortiter executa, et prima actione et paene cunctis sententiis liberata est. Quam, quia sub specie feminae uirilem animum gerebat, Androgynen appellabant.

22 Un análisis de la actuación de Hortensia lo encontramos en Guerra (2005).

Panta Rei (2015), 27 - 41 
discurso que Apiano pone en boca de Hortensia, desde el primer momento ésta reconoce que el foro no es un lugar para las mujeres. De hecho, su argumentación en contra de la confiscación de bienes se basa en que la condición femenina no permite tal hecho:

¿Por qué hemos de pagar tributos nosotras que no tenemos participación en magistraturas, honores, generalatos, ni, en absoluto, en el gobierno de la cosa pública, por las cuáles razones os enzarzáis en luchas personales que avocan en calamidades tan grandes? ${ }^{23}$

(App. BC, IV 32)

Por otro lado, según Valerio Máximo no es Hortensia quien habla, sino su padre, el afamado retórico Quinto Hortensio. Los logros de ella son en realidad los de él, ya que Hortensia no es más que la simple transmisora de los conocimientos de su padre. Pero los elogios a Hortensia acaban ahí, ya que a continuación Valerio hace alarde del carácter misógino de la cultura romana cuando señala que "si sus descendientes masculinos hubieran querido imitar su eficacia, la gran herencia de la elocuencia de Hortensio no habría terminado en un único discurso de una mujer ${ }^{24 "}$ (Val. Max., VIII, 3.3). Gran discurso, pero inútil al salir de la boca de una mujer, al tiempo que un reproche a los descendientes varones del orador.

Si las palabras de Hortensia perdían valor al ser pronunciadas por una mujer, algo parecido les ocurría a aquellas mujeres encargadas de transmitir prodigios ${ }^{25}$. Si bien la frágil naturaleza atribuida por los romanos a las mujeres hacía que éstas tuvieran mayores facultades que el hombre para la adivinación y la transmisión de la voluntad divina manifestada a través de los prodigios, al mismo tiempo resultaban incapaces de interpretarlos (Montero, 1994). Su caracterización como caprichosas, mentirosas y capaces de dejarse llevar por sus intereses personales las descartaba para éste y otros cometidos que implicasen a la sociedad romana en su conjunto (Connolly, 2007). Se acallaba así de nuevo la voz femenina, convirtiendo al varón en el único capaz de interpretar correctamente las señales de los dioses, y se evitaba la peligrosa asociación de la mujer con la magia ${ }^{26}$. Por otro lado, se debe considerar que "mientras los sacerdotes oficiales podían -y solíanmanipular la interpretación del prodigio (...), el éxtasis profético de las matronas era incontrolable y, por tanto, políticamente peligroso" (Montero, 1994, p. 72).

\section{Reflexiones finales}

A lo largo de las anteriores páginas hemos visto cómo la sociedad patriarcal romana impuso a las mujeres la prerrogativa del silencio e incluso puso a varias divinidades como personificación del mismo. La historia de Tacita Muta, de su indiscreción y castigo y posterior conversión en diosa del silencio, sirvió como ejemplo de comportamiento a las mujeres romanas. Algunas, como Sempronia, llegaron a hacer gala de este mutismo, siendo además halagada por ello por Valerio Máximo. La figura de Sempronia encuentra su opuesta en la de la charlatana descrita por Juvenal, quien habla, y además lo hace sin conocimiento, en un intento por mostrar su superioridad con respecto no sólo a las otras mujeres que conforman su auditorio, sino también a los hombres. La virtuosa y muda Sempronia diverge también de la monstruosa Afrania, quien grita como lo haría un animal y cuyo nombre se convierte en un insulto. La imagen de la mujer gritona, que produce sonidos que se esperan de un ser irracional, sirve a los romanos para excluir al género femenino de la esfera

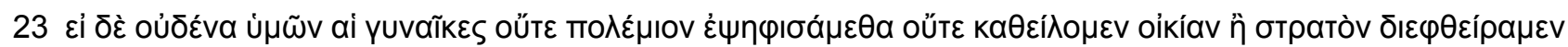

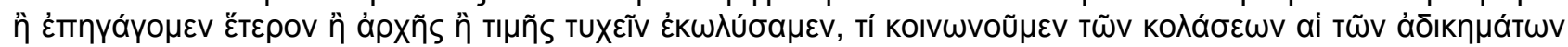
oủ $\mu \varepsilon T a \sigma X o \tilde{\sigma a ̊ ı . ~}$

24 Reuixit tum muliebri stirpe Q. Hortensius uerbisque filiae aspirauit, cuius si uirilis sexus posteri uim sequi uoluissent, Hortensianae eloquentiae tanta hereditas una feminae actione abscissa non esset.

25 Para los prodigios, ver Cid (2007b) y Rosa (2000).

26 Para la magia, ver Paulin (2011) y Stratton (2007). 
pública, copada por el ciudadano que domina el uso de la palabra y que convierte el ejercicio de la oratoria en todo un arte.

Escribe Buonopane que el mundo romano es "un mondo in cui le donne non hanno voce, non possono comunicare ed esprimere i loro sentimenti, (...) con le parole, perché non è loro concesso" (2009, p. 232). Así, privando a las mujeres del habla en el ámbito público, los varones romanos reforzaban su participación en el mismo y evitaban el peligro de que las romanas deseasen actuar en esta esfera de poder y se convirtieran así no ya en iguales a los hombres, sino incluso en superiores, tal y como se desprende del discurso de Catón. No obstante, ello no impidió que algunas mujeres se atrevieran a transgredir la norma impuesta, ya fuera en los tribunales, como es el caso de Afrania y Mesia, o en el foro, como hiciera Hortensia. Las reacciones de los varones ante un comportamiento tan opuesto al de la esposa perfecta creada por Pigmalión son diversas, incluso cuando provienen de un mismo autor, en este caso Valerio Máximo. Hortensia y Mesia son elogiadas, y por ello masculinizadas, mientras que Afrania es convertida en un monstruo. Opiniones masculinas sobre estas mujeres que indican que:

being a female is a question of represion because (...) the essence and trappings of being female -nature and dress- fail to do their jobs, are not strong enough to inhibit (cohibere) these women, the women do not fulfil their accustomed role of silence.

(Langlands, 2000, p. 177)

Con todo ello, y teniendo como referencia el mito de Tacita Muta, a lo largo de las anteriores páginas hemos intentado realizar un acercamiento a la forma en la que los romanos transmitían a sus pares femeninos los ideales patriarcales y las funciones que éstos asignaban a las mujeres. Centrándonos en la prerrogativa del silencio femenino, el presente artículo ha pretendido desentrañar un aspecto más de las relaciones de género en la Roma Antigua y devolver así su papel a las mujeres romanas, dándoles a través de nuestras palabras un espacio donde poner en valor su Historia.

\section{Abreviaturas}

AE. L'Année épigraphique: Revue des publications épigraphiques relatives a l'antiquité romaine. París. 1888-

AlJ. Hoffiller, V. y Balduin, S. Antike Inschriften aus Jugoslavien 1: Noricum und Pannonia Superior. Zagreb. 1938.

\section{Bibliografía}

Bauman, R. (1992). Women and politics in ancient Rome. Londres-Nueva York: Routledge.

Beteta, Y. (2009). Las heroínas regresan a Ítaca. La construcción de las identidades femeninas a través de la subversión de los mitos. Investigaciones feministas, 0, 163-182.

Bettini, M. (2006). Homéophonies magiques. Le rituel en l'honeur de Tacita dans Ovide, Fastes, 2, 569 sq. Revue de l'historire des religions, 2, 149-172.

Buonopane, A. (2009). Una voce di chi non aveva voce: i graffiti delle donne. EnAngeli, Ma. G. y Donati, A. (eds.), Opinione pubblica e forme di comunicazione a Roma: il linguaggio dell'epigrafia. Atti del Colloquio AIEGL-Borghesi 2007 (pp. 231-245). Faenza: Fratelli lega.

Cantarella, E. (1997). Pasado próximo. Mujeres romanas de Tácita a Sulpicia. Madrid: Cátedra.

Casamayor, S. (2015). Casta, pia, lanifica, domiseda: modelo ideal de feminidad en la Roma tardorrepublicana (ss. II-I a.C.). Ab Initio, 11, 3-23.

Cid, R. M. (2007a). Imágenes y prácticas religiosas de la sumisión femenina en la antigua Roma. El culto a Juno Lucina y la fiesta de «Matronalia». Studia Historica. Historia Antiqua, 25, 357-372.

Cid, R. M. (2007b). Las matronas y los prodigios. Prácticas religiosas femeninas en los márgenes" 
de la religión romana. Norba, 20, 11-29.

Cid, R. M. (2015). El género y los estudios históricos sobre las mujeres de la Antigüedad. Reflexiones sobre los usos y evolución de un concepto. Revista de Historiografía, 22, 25-49.

Connolly, J. (2007). The state of speech: rhetoric and political thought in Ancient Rome. Princeton: Princeton University Press.

Deline, T. L. (2009). Women in Criminal Trials in the Julio-Claudian Era. Tesis doctoral inédita.

Dixon, S. (2001). Reading Roman Women. Londres: Duckworth.

Dixon, S. (2007). Cornelia. Mother of the Gracchi. Londres-Nueva York: Routledge.

Dubordieu, A. (2003). Divinités de la parole, divinités du silence dans la Rome antique. Revue de l'histoire des religions, 220, 259-282.

Guerra, S. (2005). Autoridad y poder en los discursos de Fulvia y Hortensia. En Alfaro, C. (ed.). Protai Gynaikes: mujeres próximas al poder en la antigüedad (pp. 71-80). Valencia: Universitat de València.

Guerra, S. (2006). Mito y violencia sexuada en las Metamorfosis de Ovidio. En Molas, Ma . D. et al., La violencia de género en la antigüedad (pp. 175-182). Madrid: Instituto de la Mujer.

Höbenreich, E. (2005). Andróginas y monstruos. Mujeres que hablan en la antigua Roma. Veleia, 22, 173-182.

Kruschwitz, P. (2012). Lenguage, Sex and (Lack of) Power. Reassessing the Linguistic Discourse about Female Speech in Latin Sources. Athenaeum, 100, 197-229.

Lagarde, M. (2014). El Feminismo en mi vida. Hitos, claves y tópicos. México D. F.: Horas y Horas.

Langlands, R. (2000). Gender and Exemplarity in Valerius Maximus. Tesis doctoral inédita.

López-Medina, M. J. (2009). Diana y otras criaturas de la noche en las Metamorfosis de Ovidio. Arys, 8, 101-128.

López-Saco, J. (2009). Las cosmovisiones matriarcales y patriarcales clásicas: el valor del mito como una fuente histórica. Praesentia, 10, 1-5.

Marco, F. (2010). Muta Tacita en dos textos mágicos (AE 1958, 150; AIJ 255-257). En Atti della giornata di studio La fattura scritta (pp. 101-115). Roma: Morcelliana.

Montero, S. (1994). Diosas y adivinas. Mujer y adivinación en la Roma antigua. Madrid: Trotta.

Paulin, S. (2011). La bruja y la vieja: un cruce entre dos estereotipos. El caso horaciano. En $V$ Jornadas de Estudios Clásicos y Medievales 2011: Juventud y vejez en la Antigüedad y el Medioevo. La Plata, Argentina, del 5 al 7 de octubre de 2011. Recuperado de http://jornadasecym.fahce. unlp.edu.ar/

Pérez, I. (2011). El Fin de la Edad de los Héroes. Relaciones de género en la mitología griega. Saarbrücken: Editorial Académica Española.

Pilcher, J. y Whelehan, I. (2011). Fifty key concepts in gender studies. Londres: SAGE.

Richlin, A. (1992). The Garden of Priapus: Sexuality and Aggression in Roman Humor. Oxford: Oxford University Press.

Rodríguez, M. C. (2010). El mito de Pigmalión en textos literarios y fílmicos. Arbor. Ciencia, Pensamiento y Cultura, 741, 33-42.

Rosa, C. de la (2000). Los prodigios en Roma: superstición o manipulación. En Marcos, M. A. (coord.). Creencias y supersticiones en el mundo clásico y medieval: XIV Jornadas de Estudios Clásicos de Castilla y León (pp. 263-276). León: Servicio de Publicaciones de la Universidad de León.

Saggioro, A. (2007). Espíritus cesados. El extraño caso de "Aius Locutius". Ilu. Revista de ciencias de las religiones, 19, 155-164.

Segarra, D. (2007). El silencio de los faunos. Ilu. Revista de ciencias de las religiones, 19, 143-153.

Sissa, G. (2008). Sex and sexuality in the Ancient World. Londres: Yale University Press.

Stratton, K. B. (2007). Naming the witch: Magic, Ideology \& Stereotype in the Ancient World. Nueva York: Columbia University Press. 


\section{Fuentes}

Apiano. Historia Romana. Madrid: Gredos. 1980. [Introducción, traducción y notas de Antonio Sancho Royo].

Cicerón. De la adivinación. México D. F.: Universidad Autónoma de México. 1988. [Introducción, traducción y notas de Julio Pimentel].

Juvenal. Sátiras. Madrid: Gredos. 1991. [Introducción de Manuel Balasch y Miquel Dolç].

Macrobio. Saturnales. Madrid: Gredos. 2010 [Introducción, traducción y notas de Fernando Navarro].

Ovidio. Metamorfosis. Madrid: Akal. 1995. [Edición de Consuelo Álvarez y Rosa Ma Iglesias].

Ovidio. Fastos. Madrid: Gredos. 1988. [Introducción, traducción y notas por Bartolomé Segura].

Plauto. Rudens o La cuerda. Castellón: Universitat Jaume I. 1993. [Introducción, traducción y notas a cargo de J. Bermúdez y E. Lázaro].

Plinio. Historia natural. Madrid: Gredos. 1995. [Edición de Enrique del Barrio].

Plutarco. Vidas paralelas. Madrid: Club Internacional del Libro. 1992. [Edición de Joaquín del Moral Ruiz].

Tito Livio. Historia de Roma desde su fundación. Madrid: Gredos. 1990. [Introducción general de Ángel Sierra. Traducción y notas de José Antonio Villar Vidal].

Ulpiano. Digesto. Pamplona: Aranzadi. 1975. [Edición de Álvaro D’Ors].

Valerio Máximo. Los nueve libros de hechos y dichos memorables. Madrid: Akal. 1988. [Edición de Fernando Martín Acera]. 



\section{Panta Rei}

PANTA REI es una revista digital de investigación orientada a la Historia y otras ciencias afines. Su principal objetivo es la transmisión del conocimiento científico, dando una oportunidad también a los jóvenes investigadores que quieren abrirse camino en el estudio de las ciencias humanas y sociales. Se compone de estudios originales relacionados con la disciplina histórica así como su didáctica y difusión. Las diferentes secciones que componen la revista son: artículos de investigación, entrevistas a profesionales, recensiones de monografías de actualidad y crónicas de congresos o eventos científicos relevantes.

Todos los artículos publicados son objeto de un proceso de revisión a cargo de un mínimo de dos evaluadores, que se consideran expertos en el ámbito temático del artículo propuesto. Nuestro deseo es poder ofrecer unos contenidos rigurosos, de calidad y de interés.

EI CEPOAT (Centro de Estudios del Próximo Oriente y la Antigüedad Tardía de la Universidad de Murcia) es la institución encargada de la coordinación y gestión de la revista, desde donde anualmente se lanzará la convocatoria para aquellos que estén interesados en publicar sus trabajos, siempre relacionados con la Historia, Arqueología, Historia del Arte, Didáctica de las Ciencias Sociales, etc.

PANTA REI is a digital journal focused on History and other sciences related to it. Its main objective is the transmission of scientific knowledge by giving also an opportunity to young researchers who want to make their way in the study of human and social sciences. It is composed by original studies related to History, as well as its didactics and promotion. The different sections of this journal are: research articles, interviews to professionals, recensions on monographs about current issues and reports about congresses or relevant scientific events.

All the articles published are subject to a revision process carried out by a minimum of two reviewers who are considered to be experts in the field of the article proposed. Our wish is to offer rigorous contents with quality and being of interest to the reader.

CEPOAT (Centre of Studies of the Middle East and Late Antiquity of the University of Murcia) is the institution in charge of the coordination and management of this journal. This is the centre from where the call for papers will be launched for all the people interested in publishing their papers, always related to History, Archeology, Art History, Didactics of the Social Sciences, etc. 


\section{Normas de Publicación}

El autor se compromete a enviar trabajos originales, que no se encuentren publicados en otras revistas ni en otros idiomas. Así mismo, el mismo artículo no podrá ser presentado en otras revistas mientras dure el proceso de evaluación.

\section{Envío y presentación de originales}

Los artículos se enviarán exclusivamente a través del correo electrónico a la dirección pantarei@um.es. Los textos serán enviados en formato DOC y las imágenes en formato JPEG o TIFF, y con un tamaño mínimo de 2000 px. Éstas no aparecerán incorporadas en el texto, sino enviadas en archivo aparte y correctamente numeradas según su posición en el texto. Junto al trabajo, se rellenará y enviará un documento aparte en el que se especifiquen los datos del autor siguiendo el modelo disponible en la página Web de la revista.

Para la redacción de los trabajos se tendrá en cuenta el Manual de la American Psychological Association, en su sexta edición. La extensión máxima de los trabajos será de 30 páginas. La tipografía será Arial 11, con interlineado sencillo y sin espacio alguno entre párrafos. El texto deberá ir justificado a ambos márgenes y sin sangría en los primeros párrafos. Los márgenes serán de $2,50 \mathrm{~cm}$. En los casos en los que fuera necesario incorporar notas, éstas irán a pie de página, enumeradas consecutivamente, con tipografía Arial 10, interlineado sencillo y justificadas a ambos márgenes.

Una información más detallada se encuentra disponible en la página http://www.um.es/cepoat/ pantarei.

\section{Proceso de valoración y evaluación}

Una vez recibidos los trabajos, la Revista realizará una primera valoración. Si el trabajo enviado se ajusta a las normas de presentación propuestas, la temática es coincidente con la línea editorial de la revista y posee la calidad científica necesaria, será remitido al consejo asesor para una primera evaluación. Si no es así en este primer paso se puede rechazar directamente los documentos que incumplan claramente la línea editorial.

Será el Consejo Asesor quien indique a la revista la originalidad, relevancia, estructura, redacción, aparato bibliográfico, etc. del trabajo enviado y, para ello, se designará a dos revisores expertos externos que evaluarán cada uno de los trabajos, que pueden formar parte (o no) de este Consejo Asesor. La selección de los revisores se ajustará a la temática y características metodológicas del trabajo. El nombre y filiación de los autores serán eliminados del trabajo para su revisión, así como los revisores actuarán de manera anónima y confidencial.

Los revisores deberán rellenar un informe de evaluación que centrará su atención en aspectos tales como características formales, originalidad y novedad de los trabajos, relevancia de las propuestas y los resultados, calidad metodológica y validez científica.

Una vez terminado el proceso se decidirá la aceptación o no de los mismos y su publicación en el número que sea pertinente, así como las modificaciones susceptibles de ser realizadas para su final publicación. Dicha notificación se enviará únicamente por correo electrónico, en un plazo máximo de seis meses. 


\section{Publishing rules}

The author is committed to submit original papers not having been published in other reviews or in other languages. In this way, it is not allowed for the same paper to be presented in other reviews during the evaluation process.

\section{Submission and presentation of originals}

The articles will be exclusively submitted by email to pantarei@um.es. The texts will be submitted in DOC format and the images in JPEG or TIFF format, and with a minimum size of 2000 px. Images will not be integrated in the text but sent in another file and properly numbered according to their position in the text. Attached to the paper, a document will be filled out and sent where the author's data will be specified following the model available on the website.

The sixth edition of the Manual of the American Psychological Association will be taken into account for the writing of the papers. The length of the papers must not exceed 30 pages. Typography will be Arial 11 , with simple line spacing and no space between paragraphs. The text must be justified on both margins without indentation in the first paragraphs. Margins size will be $2.50 \mathrm{~cm}$. Where it could be necessary the incorporation of notes, they will be at the bottom of the page, consecutively numbered with typography Arial 10, simple line spacing and justified on both margins.

More detailed information is available on the website: http://www.um.es/cepoat/pantarei.

\section{Examination and assessment process}

The Journal will submit the papers to a first examination once received. If the paper follows the presentation guidelines, the subject agrees with the editorial line of this journal, and possess the scientific quality required, it will be sent to the advisory council for a first assessment. If not, the documents which clearly fail to complete the editorial line may be rejected straightaway in this first step.

The Advisory Council will indicate the originality, relevance, structure, writing, bibliography, etc. of the text to the journal; for this purpose, two outside experts will be designated to review the papers; these experts can be (or not) part of this Advisory Council. The selection of the experts will adjust to the subject and methodological characteristics of the paper. Name and affiliation of the author will be eliminated from the text for its review, in this way experts will act anonymously and confidentially.

The experts will fill out an assessment report which will focus on aspects such as formal characteristics, originality and novelty of the papers, relevance and results of the proposal, methodological quality and scientific validity.

Once the process is finished, the acceptance or not of the papers and its publication in the corresponding edition will be decided, as well as the modifications that may be done for its final publication. This notification will be sent by email within 6 months maximum. 

